\title{
Establishment of cephalometric norms for ethnic Kashmiri population using Steiner's analyses
}

\author{
Ruqaya Arif ${ }^{1}$, Mir Mudasir Gul2 , Shariq Rashid ${ }^{3}$, Wasim Manzoor Bhat ${ }^{4 *}$
}

\author{
${ }^{1}$ Senior Resident, Department of Dentistry SKIMS Medical College and Hospital, Bemina, Srinagar, Jammu \& Kashmir, INDIA. \\ ${ }^{2}$ Consultant Orthodontist, Jammu \& Kashmir, INDIA. \\ ${ }^{3}$ Department of Orthopedics, Health and Family Welfare, Govt of Jammu \& Kashmir, INDIA. \\ ${ }^{4}$ Senior Resident Department of Dentistry, Sher I Kashmir institute of Medical Sciences, Soura, Srinagar, Jammu \& Kashmir, INDIA. \\ Email: bhat wasim@yahoo.in
}

Abstract Background: The establishment of cephalometric norms for local population and their consequent clinical application contributes to a more satisfactory diagnosis and treatment planning for patients hailing from a particular ethnic background. Aim: To establish cephalometric norms for ethnic Kashmiri population using Steiner's analyses with a view to clinical application of the findings. Material and Methods: A total of 102 subjects with 51 males and 51 females with Angle's Class I molar relationship with full complement of erupted permanent teeth up to second molar in proper intercuspation were included. Cephalometric radiographs were taken and analysed by using Steiner's norms. Results: The SNB angle, ANB angle, Mandibular plane angle, lower incisor to mandibular plane angle, lower incisor to NB angle, and linear measurements of lower incisor to NB, anteroposterior length of mandible, mesio-distal location of condyle, upper first molar to NA and Lower first molar to NB in the ethnic Kashmiri subjects were significantly different from the Steiner's Caucasian norms. Conclusion: The mean values for the ethnic Kashmiri population differ from Steiner's original value, indicating craniofacial morphological variation of ethnic Kashmiri population compared to Caucasians and other groups. Keywords: Kashmiri population, Cephalometric radiographs, Steiner's norms

*Address for Correspondence:

Dr Wasim Manzoor Bhat, Senior Resident Department of Dentistry, Sher I Kashmir institute of Medical Sciences, Soura, Srinagar, Jammu \& Kashmir, INDIA.

Email: bhatwasim@yahoo.in

Received Date: 05/01/2020 Revised Date: 10/02/2020 Accepted Date: 22/03/2020

DOI: https://doi.org/10.26611/10191411

\begin{tabular}{|l|l|}
\hline \multicolumn{2}{|c|}{ Access this article online } \\
\hline Quick Response Code: & Website: \\
\hline & www.medpulse.in \\
\hline & \\
\hline
\end{tabular}

\section{INTRODUCTION}

The science of jaw proportions and measurements became much more relevant to orthodontics and this was made possible with the advent of cephalometrics. ${ }^{1}$ Radiographic cephalometry has been used extensively to study facial form and to develop norms to aid in diagnosis and treatment planning. It is also used to assess treatment progress and craniofacial growth, to predict growth for individual patients and for other tasks in orthodontic research. ${ }^{2,3}$ The establishment of cephalometric norms for local population and their consequent clinical application contributes to a more satisfactory diagnosis and treatment planning for patients hailing from a particular ethnic background. ${ }^{4}{ }_{\text {SEP }}^{i}$ IIt is evident from the studies of numerous investigators that the cephalometric norms vary among different age, sex and race. Populations differ in their character, size, growth and shape. These differences are due to a complicated interaction of genetic and environmental factors. Since Steiner's analysis was meant for American (Caucasian) population and he emphasized for modifications and adaptations on the basis of other factors such as age, race, sex and growth potential, it was realized that there is a need to develop cephalometric norms for different ethnic groups. ${ }^{1}$ Till date no study has 
been conducted on ethnic Kashmiri population which by its geographic distribution, climate and altitude differences has evolved completely as a separate ethnic group. It is therefore thought pertinent to undertake such a study for the ethnic population of Kashmir and observe various cephalometric values by means of Steiner's analysis with a view to clinical application of the findings.

\section{MATERIAL AND METHODS}

The study was carried out on the patients received in the Out-Patient Department of the department of Orthodontics and Dentofacial Orthopaedics. The sample for this study consisted of 102 subjects, 51 males and 51 females of ethnic Kashmiri origin.

Inclusion criteria

- Normal, acceptable and pleasing profile

- 18 - 30 years of age

- Angle's Class I molar relationship with full complement of erupted permanent teeth up to second molar in proper intercuspation

- No history of orthodontic treatment, gross carious lesions, periodontal disease and facial trauma.

\section{Exclusion criteria}

- Class II and Class III malocclusion. istep

- Cleft lip and cleft palate patients. iscep.

- Periodontally compromised patients. iscp.

- History of facial trauma. iscep

- Previous history of orthodontic treatment.

\section{Methodology}

Sample Size Determination

For this study, the probability of type 1 error $(\alpha)$ was fixed at $5 \%$ and probability of type 2 errors $(\beta)$ at $20 \%$. Hence, the power of the study would be $80 \%$. The sample size for this study has been determined scientifically using Cohen's $\mathrm{d}$ power formula. The following formula has been used to calculate Cohen's d: Cohen's d = M1-M2/SD. Where, M1 is the mean of target value of experimental group, M2 is the mean of the target value of control group and SD is the standard deviation. So, for the power of the study of $80 \%$, the sample size of 51 subjects was selected for each group. Based on the above calculations, the study included a total of 102 subjects with 51 males and 51 females. The level of significance was set at 0.05 . The linear measurements were recorded with a measuring scale up to $0.5 \mathrm{~mm}$ correction. The angular measurements were recorded with a protractor up to $0.5^{\circ}$ corrections. Statistical calculations performed included mean, standard deviation, standard error and student's ' $t$ ' test for each parameter. Statistical comparisons were done by the ' $t$ ' test. Informed consent regarding the benefits and protocol of study was obtained from all patients.
Table 1: Parameters used in Steiner's analysis

\begin{tabular}{ccc}
\hline S.N. & Parameter & Average value \\
\hline 1. & SNA (angle) & $82^{\circ}$ \\
2. & SNB (angle) & $80^{\circ}$ \\
3. & ANB (angle) & $2^{\circ}$ \\
4. & GoGn-SN (angle) & $32^{\circ}$ \\
5. & Occlusal plane -SN (angle) & $14.5^{\circ}$ \\
6. & $1-N A(m m)$ & $4 \mathrm{~mm}$ \\
7. & $1-\mathrm{NA}$ (angle) & $22^{\circ}$ \\
8. & $1-N B(\mathrm{~mm})$ & $4 \mathrm{~mm}$ \\
9. & $1-N B($ angle) & $25^{\circ}$ \\
10. & $1-1$ (angle) & $130^{\circ}$ \\
11. & $1-$ GoGn (angle) & $93^{\circ}$ \\
12. & S-L (mm) & $51 \mathrm{~mm}$ \\
13. & S-E (mm) & $22 \mathrm{~mm}$ \\
14. & $6-\mathrm{NA}(\mathrm{mm})$ & $27 \mathrm{~mm}$ \\
15. & $6-N B(\mathrm{~mm})$ & $23 \mathrm{~mm}$ \\
\hline
\end{tabular}

\section{Radiographic technique}

To have standardized cephalometric radiographs, it became important that all the radiographs were taken from the same X-ray machine with the subjects in the natural head position, with teeth in maximum intercuspation and lips at repose. All the lateral cephalometric radiographs were taken by the same operator from the standardized Orthophos XG5 DS CEPH (SIRONA) on a standard Konica Minolta $8 \times 10$ inch film with an anode to midsubject distance of 5 feet by the same operator. Natural head position was obtained by asking the subject to look straight ahead such that the visual axis was parallel to the floor. Thyroid shield and lead apron were worn by the subject to reduce radiation exposure. All the films were exposed with $64 \mathrm{KVp}, 8 \mathrm{~mA}$ and an exposure time of 9 second S. Lateral cephalogram were traced upon an A4 size acetate paper with a $2 \mathrm{~B}$ or $3 \mathrm{HB}$ hard lead pencil over well-illuminated viewing screen. The linear measurements were recorded with a measuring scale up to a precision of $0.5 \mathrm{~mm}$. The angular measurements were analysed with a protractor up to a precision of $0.5^{\circ}$.

Statistical analysis

Various statistical methods employed in the study were mean values, standard deviations and standard error.sEpistudent's ' $t$ ' test was used to analyse the observations during the study. Various parameters studied were tested accordingly to determine the significance of the variations observed between the male and female subjects.

\section{RESULTS}

SNA angle:

The mean value of SNA angle in present study was $82.25^{\circ}$ for males and $81.06^{\circ}$ for females. The mean value of SNA angle for Kashmiri population was $81.66^{\circ}$. The mean SNA angle is almost same as that of Caucasians $\left(82^{\circ}\right)$ with statistically insignificant difference (P-value 0.27), 
indicating that maxillary apical base is normally inclined relative to cranial base. The difference between male and female values was also statistically insignificant (P-value 0.055).

SNB angle:

The mean value of SNB angle in the present study was $78.25^{\circ}$ for males and $78.20^{\circ}$ for females. The mean SNB value for Kashmiri population was $78.23^{\circ}$. The mean value of SNB angle in the present study is significantly less than those presented by Steiner $\left(80^{\circ}\right)$, indicating mandibular apical base is posteriorly inclined relative to cranial base (P-value $<0.001)$. The difference between male and female values was also statistically insignificant (P-value 0.923 ). ANB angle:

The mean value of ANB angle for Kashmiri population was $3.43^{\circ}$ which is slightly more than those presented by Steiner $\left(2^{\circ}\right)$, indicating greater tendency towards bialveolar protrusion. There is statistically significant difference in ANB angle $(\mathrm{P}$-value $<0.001)$ between Caucasians and Kashmiri population. The mean value of ANB angle for males was $4.00^{\circ}$ and $2.86^{\circ}$ for females. There was a statistically significant difference ( $\mathrm{P}$ value $<0.001)$ in $\mathrm{ANB}$ value between male $\left(4.00^{\circ}\right)$ and female $\left(2.86^{\circ}\right)$ Kashmiri subjects.

\begin{tabular}{|c|c|c|c|}
\hline Measured parameter & Males & Females & $\begin{array}{l}\text { Total } \\
\text { sample }\end{array}$ \\
\hline Mean SNB angle & $78.25^{\circ}$ & $78.20^{\circ}$ & $78.23^{\circ}$ \\
\hline Mean ANB angle & $4.00^{\circ}$ & $2.86^{\circ}$ & $3.43^{\circ}$ \\
\hline Mean Mandibular plane angle & $28.16^{\circ}$ & $29.10^{\circ}$ & $28.63^{\circ}$ \\
\hline Mean Occlusal plane angle & $14.57^{\circ}$ & $14.75^{\circ}$ & $14.66^{\circ}$ \\
\hline $\begin{array}{l}\text { Mean Maxillary incisor position } \\
\text { relative to NA (mm) }\end{array}$ & 3.49 & 4.24 & 3.86 \\
\hline $\begin{array}{l}\text { Mean Maxillary incisor inclination } \\
\text { relative to NA line (degree) }\end{array}$ & $21.59^{\circ}$ & $23.73^{\circ}$ & $22.66^{\circ}$ \\
\hline $\begin{array}{l}\text { Mean Mandibular incisor position } \\
\text { relative to NB }(\mathrm{mm})\end{array}$ & 4.53 & 4.39 & 4.46 \\
\hline $\begin{array}{l}\text { Mean Mandibular incisor inclination } \\
\text { relative to NB line (degree) }\end{array}$ & $23.33^{\circ}$ & $23.80^{\circ}$ & $23.57^{\circ}$ \\
\hline Mean Interincisal angle & $132.33^{\circ}$ & $130.4^{\circ}$ & $131.39^{\circ}$ \\
\hline $\begin{array}{l}\text { Mean lower incisor to mandibular } \\
\text { plane angle }\end{array}$ & $96.63^{\circ}$ & $96.08^{\circ}$ & $96.35^{\circ}$ \\
\hline Mean S-L $(\mathrm{mm})$ & 50.04 & 46.98 & 48.51 \\
\hline Mean S-E (mm) & 20.69 & 20.12 & 20.40 \\
\hline $\begin{array}{l}\text { mean Maxillary first molar position } \\
\text { relative to NA }(\mathrm{mm})\end{array}$ & 26.33 & 24.69 & 25.51 \\
\hline $\begin{array}{l}\text { mean Mandibular first molar position } \\
\text { relative to NB }(\mathrm{mm})\end{array}$ & 19.20 & 18.69 & 18.94 \\
\hline
\end{tabular}

Mandibular plane angle:

The mandibular plane angle suggests growth pattern in individuals. The mean value of mandibular plane angle for Kashmiri population was $28.63^{\circ}$ which is smaller compared to Caucasians $\left(32^{\circ}\right)$, indicating that Kashmiri population exhibits horizontal growth pattern compared to
Caucasians. There is a statistically significant difference in mandibular plane angle (P-value $<0.001)$ between Kashmiri population and Caucasians. The mean mandibular plane angle was $28.16^{\circ}$ for males and $29.10^{\circ}$ for females with statistically insignificant difference (Pvalue 0.419 ).

Occlusal plane angle:

In the present study, the mean of occlusal plane angle for Kashmiri population was 14.660 that is same as measurements given by Steiner $\left(14.5^{\circ}\right)$. There is no statistically significant difference between Kashmiri population and Caucasians (P-value 0.72). There was no marked variation in occlusal plane angle between male and female Kashmiri subjects with mean value of $14.57^{\circ}$ for males and $14.75^{\circ}$ for female subjects (P-value 0.842 ).

Maxillary incisor position relative to NA [I - NA $(\mathrm{mm})]$ :

The upper incisor to N-A reading in millimetres provides information on the relative forward or backward positioning of the incisor teeth to N-A line. The mean value in present study for Kashmiri population was $3.86 \mathrm{~mm}$ which is almost same as presented by Steiner. There is no statistically significant difference in maxillary incisor position relative to NA line between Kashmiri population and Caucasians (P-value 0.34). The mean upper incisor to $\mathrm{N}$-A reading was $3.49 \mathrm{~mm}$ for males and $4.24 \mathrm{~mm}$ for females which was statistically significant (Pvalue $<0.008$ ).

Maxillary incisor inclination relative to NA line [I-NA (degrees)]:

The upper incisor to N-A reading in degrees indicates the relative angular relationship of the upper incisor teeth to $\mathrm{N}-\mathrm{A}$ line. The mean value of maxillary incisor position in degrees in present study for Kashmiri population was $22.66^{\circ}$ and is same as presented by Steiner $\left(22^{\circ}\right)$. There is no statistically significant difference in maxillary incisor inclination relative to NA line between Kashmiri population and Caucasians (P-value 0.19). However, there was a statistically significant difference in maxillary incisor inclination relative to NA line $(\mathrm{P}$-value $<0.030)$ between male and female Kashmiri subjects with mean values of $21.59^{\circ}$ for males and $23.73^{\circ}$ for females. The lower incisor to N-B reading in millimetres provides information on the relative forward or backward positioning of the incisor teeth to N-B line. The mean value in present study for Kashmiri population was $4.46 \mathrm{~mm}$ which is significantly higher as presented by Steiner $(4 \mathrm{~mm})$, indicating that lower incisors are forwardly placed relative to NA line. There is statistically significant difference $(\mathrm{P}$-value $<0.007)$ in mandibular incisor position relative to NB line between Kashmiri population and Caucasians. The mean lower incisor to N-B reading was $4.53 \mathrm{~mm}$ for males and $4.39 \mathrm{~mm}$ for females. However, the 
difference between the values was statistically insignificant (P-value 0.683).

NB (degrees)

The lower incisor to N-B reading in degrees indicates the relative angular relationship of the lower incisor teeth to $\mathrm{N}-\mathrm{B}$ line. The mean value of mandibular incisor inclination in degrees in present study for Kashmiri population was $23.33^{\circ}$ for males and $23.80^{\circ}$ for females. The mean value for Kashmiri population was $23.57^{\circ}$ that is less as compared to Caucasians $\left(25^{\circ}\right)$. There is statistically significant difference $(\mathrm{P}$-value $<0.013)$ in mandibular incisor inclination relative to NB line between Kashmiri population and Caucasians. However, there was no statistically significant difference in mandibular incisor inclination relative to NB line between male $\left(23.33^{\circ}\right)$ and female $\left(23.80^{\circ}\right)$ Kashmiri subjects (P-value 0.679). Interincisal angle relates the relative position of the upper incisor to that of the lower incisor. The mean value of interincisal angle in present study for Kashmiri population was $131.39 \mathrm{o}$ that is almost same as given by Steiner (Pvalue 0.11 ). The mean interincisal angle was $132.33^{\circ}$ for males and $130.45^{\circ}$ for female subjects. The difference between the male and female subject values was statistically insignificant (P-value 0.274$)$. Lower incisor to mandibular plane angle indicates relative angular relationship of lower incisor to mandibular plane i.e. whether these are proclined or retroclined relative to mandibular plane. The mean value for Kashmiri population was $96.35^{\circ}$ that is significantly higher as compared to Caucasians as presented by Steiner $\left(93^{\circ}\right)$, indicating that lower incisors are proclined compared to Caucasians. There is statistically significant difference $(\mathrm{P}-$ value $<0.001$ ) in lower incisor to mandibular plane angle for Kashmiri population compared to Caucasians. The mean value of lower incisor to mandibular plane angle was $96.63^{\circ}$ for males and $96.08^{\circ}$ for females, the difference being statistically insignificant (P-value 0.658 ).

S-L measurement (anterioposterior length of the mandible): : iš

The measurement S-L records anterioposterior length of the mandible. The mean value of S-L measurement for Kashmiri population was $48.51 \mathrm{~mm}$ that is significantly lesser compared to Caucasians as presented by Steiner $(51 \mathrm{~mm})$. There is statistically significant difference in S-L measurement $(\mathrm{P}$-value $<0.002)$ for Kashmiri population compared to Caucasians. The mean value of S-L measurement for males was $50.04 \mathrm{~mm}$ and females had the mean value of $46.98 \mathrm{~mm}$ with statistically significant difference (P-value $<0.0470)$.

S-E measurement (mesiodistal mandibular condylar position):

The measurement $\mathrm{S}-\mathrm{E}$ determines the mesiodistal mandibular condylar position. The mean value measured for S-E for Kashmiri population was $20.40 \mathrm{~mm}$ which is significantly lesser when compared to Caucasians as presented by Steiner $(22 \mathrm{~mm})$. There is statistically significant difference in S-E measurement (Pvalue $<0.001$ ) for Kashmiri population compared to Caucasians. The mean value measured for S-E for males was $20.69 \mathrm{~mm}$ and mean value for females was $20.12 \mathrm{~mm}$. The difference between male and female subjects was statistically insignificant (P-value 0.222).

Maxillary first molar position relative to NA [6-NA (mm)]:

This measurement is useful at a later date in determining whether or not the molar has moved forward or backward in relationship to this line. The mean value measured for maxillary first molar position relative to NA for Kashmiri population was $25.51 \mathrm{~mm}$ which is significantly lesser compared to Caucasians as presented by Steiner $(27 \mathrm{~mm})$. There is statistically significant difference for maxillary first molar position relative to NA (Pvalue $<0.001$ ) for Kashmiri population compared to Caucasians. The mean value measured for maxillary first molar position relative to NA was $26.33 \mathrm{~mm}$ for male subjects and $24.69 \mathrm{~mm}$ for female subjects. The difference between male and female subjects was statistically significant $(\mathrm{P}$-value $<0.001)$.

Mandibular first -NB ( $\mathrm{mm})$ :

This measurement is useful for future reference for evaluation of lower molar position. The mean value measured for mandibular first molar position relative to NB for Kashmiri population was $18.94 \mathrm{~mm}$ that is significantly lesser compared to Caucasians as presented by Steiner $(23 \mathrm{~mm})$. There is statistically significant difference for mandibular first molar position relative to NB (P-value $<0.001)$ for Kashmiri population compared to Caucasians. The mean value measured for mandibular first molar position relative to NB was $19.20 \mathrm{~mm}$ for males and $18.69 \mathrm{~mm}$ for females which is statistically insignificant (P-value 0.289).

\section{DISCUSSION}

The cephalometric norms of different ethnic groups established in various studies show that normal measurements for one group are not necessarily normal for another group; each ethnic group must be treated according to its own characteristics. Kashmiri population is completely a different ethnic group with features imbibed from various ethnic groups, due to its geographic distribution, climate and altitude differences. Thus, the craniofacial features are affected by both genetic and environmental factors and the craniofacial features of the ethnic Kashmiri population are entirely different from other ethnic groups. ${ }^{5-8}$ The present study tried to establish cephalometric norms and standards for ethnic Kashmiri 
young adults according to Steiner's analysis. Cephalometrically 15 parameters have been used of which six are linear and nine are angular measurements. The parameters have been taken from Steiner's original article. ${ }^{9}$

SNA angle

The mean value of SNA angle in present study for Kashmiri population is same as Caucasians, depicting that the maxillary apical base of Kashmiri young adults is same as Caucasians, and statistically there is no significant difference between two groups. There was also no statistically significant difference between male and female Kashmiri population. The measurement of SNA angle for Kashmiri population $\left(81.66^{\circ}\right)$ is in agreement with the studies done by Miura et al. ${ }^{10}$ on Japanese population $\left(81.3^{\circ}\right)$, Gleis et al. ${ }^{11}$ on Israeli population $\left(81.63^{\circ}\right)$, Grover et al. ${ }^{12}$ on Haryana population $\left(82.78^{\circ}\right)$ and Park et al. ${ }^{13}$ on Korean population $\left(81.15^{\circ}\right)$.

SNB angle

The mean value of SNB angle in the present study is significantly less in Kashmiri population $\left(78.23^{\circ}\right.$ ) than those presented by Steiner $\left(80^{\circ}\right)$, indicating mandibular apical base is posteriorly inclined relative to cranial base. There is a statistically significant difference in SNB angle between Caucasians and Kashmiri population $(\mathrm{P}<0.001)$. However, there was no statistically significant difference in SNB value between male and female Kashmiri population. The SNB angle found in present study is in agreement with the studies done by Park et al. ${ }^{13}$ on Korean population $\left(78.7^{\circ}\right)$, Gleis et al. ${ }^{11}$ on Israeli population $\left(78.2^{\circ}\right)$.

ANB angle

The mean value of ANB angle for Kashmiri population $\left(3.43^{\circ}\right)$ is slightly more than those presented by Steiner $\left(2^{\circ}\right)$, indicating greater tendency towards bialveolar protrusion. There is statistically significant difference in ANB angle $(\mathrm{P}<0.001)$ between Caucasians and Kashmiri population. There was also a statistically significant difference in ANB value between male and female $(\mathrm{P}<0.001)$ Kashmiri subjects. The ANB angle found in present study is in agreement with the studies done by Gleis et al. ${ }^{11}$ on Israeli population $\left(3.43^{\circ}\right)$ and Patel et al. ${ }^{14}$ on Guajarati population $\left(3.01^{\circ}\right)$, Grover et al. ${ }^{12}$ on Haryana population $\left(3.18^{\circ}\right)$ and Baruah et al..$^{15}$ on Assamese population $\left(3.01^{\circ}\right)$.

Mandibular plane angle

The mandibular plane angle suggests growth patterns in individuals. The mean value of mandibular plane angle $\left(28.63^{\circ}\right)$ for Kashmiri population is smaller compared to Caucasians $\left(32^{\circ}\right)$, indicating that Kashmiri population exhibits horizontal growth pattern compared to Caucasians. There was a statistically significant difference in mandibular plane angle $(\mathrm{P}<0.001)$ between Kashmiri population and Caucasians. However, there was no statistically significant difference in mandibular plane angle between male and female Kashmiri subjects. This finding is in agreement with study done by Atit et al. ${ }^{2}$ on Maratha population $\left(28.1^{\circ}\right)$.

Occlusal plane angle

In the present study, the mean of occlusal plane angle for Kashmiri population (14.66o) is same as measurements given by Steiner $\left(14.5^{\circ}\right)$. There is no statistically significant difference between Kashmiri population and Caucasians. There was no marked variation in occlusal plane angle between male and female Kashmiri subjects. The occlusal plane angle value in this study is in agreement with study done by Grover et al. ${ }^{12}$ on Haryana population $\left(14.36^{\circ}\right)$, Atit et al..$^{2}$ on Maratha population $\left(14.4^{\circ}\right)$ and AlJasser $\mathrm{NM}^{16}$ on Saudi population $\left(14.039^{\circ}\right)$.

Maxillary incisor position relative to NA ( $\mathrm{mm})$

The upper incisor to $\mathrm{N}-\mathrm{A}$ reading in millimetres provides information on the relative forward or backward positioning of the incisor teeth to $\mathrm{N}-\mathrm{A}$ line. The mean value in present study for Kashmiri population $(3.86 \mathrm{~mm})$ is almost same as presented by Steiner. There is no statistically significant difference in maxillary incisor position relative to NA line between Kashmiri population and Caucasians. However, there was statistically significant difference $(\mathrm{P}<0.008)$ between male and female Kashmiri subjects. This is in agreement with study done by Baruah et al. ${ }^{15}$ on Assamese population ( $\left.4.11 \mathrm{~mm}\right)$.

Maxillary incisor inclination relative to NA line (degrees)

The upper incisor to N-A reading in degrees indicates the relative angular relationship of the upper incisor teeth to $\mathrm{N}-\mathrm{A}$ line. The mean value of maxillary incisor position in degrees in present study for Kashmiri population $\left(22.66^{\circ}\right)$ is almost same as presented by Steiner $\left(22^{\circ}\right)$. There is no statistically significant difference in maxillary incisor inclination relative to NA line between Kashmiri population and Caucasians. However, there was statistically significant difference in maxillary incisor inclination relative to NA line $(\mathrm{P}<0.030)$ between male and female Kashmiri subjects. This is in agreement with study done by Valiathan $\mathrm{A}^{17}$ on Indian residents in U.S.A $\left(22.8^{\circ}\right)$.

Mandibular incisor position relative to $\mathrm{NB}(\mathrm{mm})$

The lower incisor to N-B reading in millimetres provides information on the relative forward or backward positioning of the incisor teeth to N-B line. The mean value in present study for Kashmiri population $(4.46 \mathrm{~mm}$ ) is significantly higher as presented by Steiner $(4 \mathrm{~mm})$, indicating that lower incisors are forwardly placed relative to NA line. There is statistically significant difference $(\mathrm{P}<0.007)$ in mandibular incisor position relative to $\mathrm{NB}$ line between Kashmiri population and Caucasians. 
However, there was no statistically significant difference between male and female Kashmiri subjects. This is in agreement with study done by Baruah et al. ${ }^{15}$ on Assamese population $(4.63 \mathrm{~mm})$ and Sharma $\mathrm{JN}^{18}$ on Nepalese population $(4.8 \mathrm{~mm})$.

Mandibular incisor inclination relative to NB line (degrees)

The lower incisor to N-B reading in degrees indicates the relative angular relationship of the lower incisor teeth to $\mathrm{N}-\mathrm{B}$ line. The mean value of mandibular incisor inclination in degrees in present study for Kashmiri population $\left(23.57^{\circ}\right)$ is lesser compared to Caucasians as presented by Steiner $\left(25^{\circ}\right)$. There is statistically significant difference $(\mathrm{P}<0.013)$ in mandibular incisor inclination relative to NB line between Kashmiri population and Caucasians. However, there was no statistically significant difference in mandibular incisor inclination relative to NB line between male and female Kashmiri subjects. This is in agreement with study done by Sharma $J \mathrm{~N}^{18}$ on Nepalese population $\left(23.8^{\circ}\right)$.

Interincisal angle

Interincisal angle relates the relative position of the upper incisor to that of the lower incisor. The mean value of interincisal angle in present study for Kashmiri population $(131.390)$ is same as given by Steiner. There is no statistically significant difference in interincisal angle between Kashmiri population and Caucasians and also between male and female subjects. This finding is in agreement with study done by Garcia $\mathrm{CJ}^{19}$ on Mexican Americans $\left(130^{\circ}\right)$.

Lower incisor to mandibular plane angle

Lower incisor to mandibular plane angle indicates relative angular relationship of lower incisors to mandibular plane i.e. whether these are proclined or retroclined relative to mandibular plane. The mean value is significantly higher $\left(96.35^{\circ}\right)$ for Kashmiri population compared to Caucasians as presented by Steiner $\left(93^{\circ}\right)$, indicating that lower incisors are proclined compared to Caucasians. There is statistically significant difference $(\mathrm{P}<0.001)$ in lower incisor to mandibular plane angle for Kashmiri population compared to Caucasians. However, there was no statistically significant difference between male and female Kashmiri subjects. This finding is in agreement with studies done by Kowalski et al..$^{20}$ on White American adult population $\left(96.58^{\circ}\right)$.

S-L measurement (anterioposterior length of the mandible)

The measurement S-L records anterioposterior length of the mandible. The mean value of S-L measurement is significantly lesser for Kashmiri population $(48.51 \mathrm{~mm})$ compared to Caucasians as presented by Steiner $(51 \mathrm{~mm})$. There is statistically significant difference in S-L measurement $(\mathrm{P}<0.002)$ for $\mathrm{Kashmiri}$ population compared to Caucasians. There was also statistically significant difference between male and female Kashmiri subjects $(\mathrm{P}<0.0470)$.

S-E measurement (mesiodistal mandibular condylar position)

The measurement S-E determines mesiodistal mandibular condylar position. The mean value measured for S-E is significantly lesser for Kashmiri population $(20.40 \mathrm{~mm})$ compared to Caucasians as presented by Steiner $(22 \mathrm{~mm})$. There is statistically significant difference in S-E measurement $(\mathrm{P}<0.001)$ for Kashmiri population compared to Caucasians. However, there was no statistically significant difference between male and female Kashmiri subjects. This finding is in agreement with studies done by Baruah et al. ${ }^{15}$ on Assamese population $(20.97 \mathrm{~mm})$ and Patel et al. ${ }^{14}$ on Guajarati population $(20.6 \mathrm{~mm})$.

Maxillary first molar position relative to NA $(\mathrm{mm})$

This measurement is useful at a later date in determining whether or not the molar has moved forward or backward in relationship to this line. The mean value measured for maxillary first molar position relative to NA is significantly lesser for Kashmiri population $(25.51 \mathrm{~mm})$ compared to Caucasians as presented by Steiner $(27 \mathrm{~mm})$. There is statistically significant difference for maxillary first molar position relative to NA $(\mathrm{P}<0.001)$ for Kashmiri population compared to Caucasians. There was also statistically significant difference between male and female Kashmiri subjects $(\mathrm{P}<0.001)$. This finding is in agreement with studies done by Kowalski et al. ${ }^{20}$ on White American adult population $(25.14 \mathrm{~mm})$.

Maxillary first molar position relative to NA $(\mathrm{mm})$

This measurement is useful for future reference for evaluation of lower molar position. The mean value measured for mandibular first molar position relative to NB is significantly lesser for Kashmiri population (18.94 $\mathrm{mm}$ ) compared to Caucasians as presented by Steiner (23 $\mathrm{mm})$. There is statistically significant difference for mandibular first molar position relative to NB $(\mathrm{P}<0.001)$ for Kashmiri population compared to Caucasians. However, there was no statistically significant difference between male and female Kashmiri subject. This finding is in agreement with studies done by Kowalski et al. ${ }^{20}$ on Sioux Indian population $(18.36 \mathrm{~mm})$. Cephalometric studies on non-Caucasians indicated that there were measurable skeletal and dental differences compared to Caucasians. In the modern biologic era, variations occur and are not perceived as unnatural. Therefore, the present study agreed to the fact that the norms and standards of one ethnic group could not be applied without modification for another group. The mean values for measurements of one ethnic group could not be considered normal for others. For instance; SNB angle, ANB angle, mandibular plane 
angle, lower incisor to mandibular plane angle, lower incisor to NB angle, and linear measurements of lower incisor to NB, S-L measurement, S-E measurement, upper first molar to NA and lower first molar to NB significantly differ from Caucasian norms. Thus the established norms can be used as a reference guideline to know the extent of discrepancy in a particular case of ethnic Kashmiri population. Therefore, each different ethnic group would best be treated according to its individual characteristics in order to achieve an aesthetically pleasing face. There are infinite morphological variations of the biological parameters, which can be attributed to multiple intricate developmental processes that are affected by both genetic and environmental factors. The Kashmiri population has evolved completely as a separate ethnic group by its geographic distribution, climate and altitude differences. Thus the establishment of cephalometric norms for ethnic Kashmiri population and their consequent clinical application would greatly contribute to a more satisfactory diagnosis and treatment planning for patients hailing from this particular ethnic background.

\section{CONCLUSION}

The results showed that most of the mean values for the ethnic Kashmiri population differ from Steiner's original value, indicating craniofacial morphological variation of ethnic Kashmiri population compared to Caucasians and other groups. The results of this study support the fact that the standards and norms established for one ethnic group should not be applied for another group.

\section{REFERENCES}

1. Kharbanda OP. Steiner's Analysis. Orthodontics: Diagnosis and management of malocclusion and dentofacial deformities. Ed. 1st Elsevier; 2009:172-176.

2. Atit MB, Deshmukh SV, Rahalkar J, Subramanian V, Naik C and Darda M. Mean values of Steiner's, Tweed's, Ricketts and McNamara analyses in Maratha ethnic population: a Cephalometric study. APOS Trends Orthod 2013;3(5):137151.

3. Proffit WR, Fields HW, Sarver DM and Ackerman JL. Contemporary Orthodontics. Ed. 5th Elsevier; 2013:184-194.

4. Zubair, Graber, Vanarsdall and Vig. Special considerations in diagnosis and treatment planning. Orthodontics: Current principles and techniques. Ed. 5th Elsevier; 2005:36-39.

5. Jantz RL. The meaning and consequences of morphological variation. American Anthropological Association 2004:1-17.

6. Gupta R and Basu A. Variations in body dimensions in relation to altitude among the Sherpa's of the eastern Himalayas. Annals of human biology 1981; 8 (2):145- 151

7. Paschetta C, Azevedo S, Castillo L, Abadias NM, M Hernandez M. Lieberman DE, and Gonzalez-Jose R. The Influence of masticatory loading on craniofacial morphology. A test case across technological transitions in the Ohio valley. Am J Phys Anthropol 2010; 141:297-314.

8. Hubbe M, Hanihara T, Harvati K. Climate signatures in the morphological differentiation of worldwide modern human populations. The anatomical record 2009; 292:1720-1733.

9. Steiner CC. Cephalometrics for you and me. Am J Orthod $1953 ; 39: 729-54$ s.

10. Miura F, Inoue N, Suzuki K. Cephalometric standards for the Japanese according to Steiner's analysis. Am. J Orthod 1965; 51 (4): 288-295.

11. Gleis Ruth, Brezniak Naphtali and Liberman Myron. Israeli cephalometric standards compared to Down's and Steiner's analyses. Angle Orthod 1990; 60 (1):35-40.

12. Grover VK, Grover VR, Bhutani RK. Hard tissue cephalometric observations based on Steiner's analysis in young adults in Haryana. J Indian Dental Association 1998; 69. SEP

13. Park IC, Bowman D, Klapper L. A cephalometric study of Korean adults. Am J Orthod 1989; 96:154-159.

14. Patel DP, Trivedi R. Photography versus lateral cephalogram: Role in facial diagnosis. Indian Journal of Dental Research, 2013.

15. Baruah N, Bora M. Cephalometric evaluation based on Steiner's analysis on young adults of Assam. J Indian Orthod Soc 2009; 43:17-22.

16. Al-Jasser Nasser M. Cephalometric evaluation of craniofacial variation in normal Saudi population according to Steiner's analysis. Saudi Medical Journal 2000; 21 (8):746-750.

17. Valiathan A. racial comparison of dentofacial cephalometric norms using Steiner's analysis. J Indian Orthod Soc 1979; 11 $(1-2): 8-11$.

18. Sharma JN. Steiner's cephalometric norms for the Nepalese population. J Orthod 2011; 38:21-31.

19. Garcia CJ. Cephalometric evaluation of Mexican Americans using the Down's and Steiner's analyses. Am J Orthod 1975; 68:67-74

20. Kowalski CJ, Nasjleti CE and Walker GF. Dentofacial variations within and between four groups of adult American males. Angle Orthod 1975; 45 (2):146-151.

Source of Support: None Declared Conflict of Interest: None Declared

Policy for Articles with Open Access:

Authors who publish with MedPulse International Journal of Dentistry (Print ISSN: 2579-1125) (Online ISSN: 2636-4603) agree to the following terms: Authors retain copyright and grant the journal right of first publication with the work simultaneously licensed under a Creative Commons Attribution License that allows others to share the work with an acknowledgement of the work's authorship and initial publication in this journal.

Authors are permitted and encouraged to post links to their work online (e.g., in institutional repositories or on their website) prior to and during the submission process, as it can lead to productive exchanges, as well as earlier and greater citation of published work. 